Tropical Journal of Pharmaceutical Research September 2021; 20 (9): 1969-1974

ISSN: $1596-5996$ (print); 1596-9827 (electronic) (C) Pharmacotherapy Group, Faculty of Pharmacy, University of Benin, Benin City, 300001 Nigeria

\title{
Assessment of lifestyle, herbs, dietary and pharmacological preventive measures used among the public in Jordan to boost immunity during COVID-19 pandemic
}

\author{
Reem Issa ${ }^{1 *}$, Dima Albals ${ }^{2}$, Ala Yehya ${ }^{3}$, Fayez Shriedh ${ }^{4}$ \\ ${ }^{1}$ Department of Pharmaceutical Sciences, Pharmacological \& Diagnostic Research Centre (PDRC), Faculty of Pharmacy, Al- \\ Ahliyya Amman University, Amman, ${ }^{2}$ Department of Medicinal Chemistry and Pharmacognosy, ${ }^{3}$ Department of Clinical \\ Pharmacy \& Pharmacy Practice, Faculty of Pharmacy, Yarmouk University, Irbid, ${ }^{4}$ Luminus Technical University College, \\ Amman, Jordan
}

*For correspondence: Email: r.issa@ammanu.edu.jo; Tel: +962 $53500211 / 17$ (7 lines)

\begin{abstract}
Purpose: To assess the methods and practices for strengthening immunity and limiting virus spread among the public during the COVID-19 pandemic

Method: A questionnaire was designed and distributed to the public in Jordan. Socio-demographic characteristics, lifestyle practices, and intakes of herbs, vitamins, diet, and medications during the COVID-19 pandemic were assessed.

Results: A total of 1048 participants completed the survey, $75 \%$ of which were females and $60 \%$ were in the age group of 18 - 34 years. The majority (75 \%) agreed that staying at home along with social distancing would be their best protective measure, combined with hygienic practices and disinfection (71 \%). Ginger and mint (49 and $45 \%)$, vitamins $D$ and C (52 and $34 \%$;) were predominantly used. Of the participants, 77 and $66 \%$, respectively increased their consumption of citrus fruits and foods rich in vitamin C, when they experienced influenza-like symptoms, while 13 and $18 \%$ of the participants used antibiotics and paracetamol, respectively. Moreover, 61 and $63 \%$ of participants were aware of the guidelines on the use of antibiotics and NSAIDs for the treatment of viral infections.

Conclusion: The public practices reflect the positive beliefs about lifestyle practices, and the use of herbs, vitamins, dietary supplements, and medication intake. There is a need to promote healthy practices and increase awareness of rational drug use.
\end{abstract}

Keywords: Lifestyle, Pharmacology, Food, Herbs, Vitamins, Immune system, COVID-19

\begin{abstract}
This is an Open Access article that uses a funding model which does not charge readers or their institutions for access and distributed under the terms of the Creative Commons Attribution License (http://creativecommons.org/licenses/by/4.0) and the Budapest Open Access Initiative (http://www.budapestopenaccessinitiative.org/read), which permit unrestricted use, distribution, and reproduction in any medium, provided the original work is properly credited.

Tropical Journal of Pharmaceutical Research is indexed by Science Citation Index (SciSearch), Scopus, International Pharmaceutical Abstract, Chemical Abstracts, Embase, Index Copernicus, EBSCO, African Index Medicus, JournalSeek, Journal Citation Reports/Science Edition, Directory of Open Access Journals (DOAJ), African Journal Online, Bioline International, Open-J-Gate and Pharmacy Abstracts
\end{abstract}

\section{INTRODUCTION}

The World Health Organization announced a newly emerged Severe Acute Respiratory Syndrome (SARS) Corona virus named
"COVID-19", which has spread rapidly around the world [1]. Stringent public health and social measures have therefore been put in place worldwide to slow the fast spread of the disease. 
Older people and those with underlying medical problems like cardiovascular disease, diabetes, chronic respiratory disease, and cancer are more likely to develop serious illness [2]. Clinically, a specific adaptive immune response induced by the novel corona virus infection during the incubation and non-severe stages are required, to eliminate the virus and to prevent the advancement of the disease to severe stages. Therefore, strategies to boost immune responses (anti-sera or pegylated IFNa) at this stage are certainly important [3]. In this context, the increase in the consumption of natural products has been generating renewed interest.

There are herbs and vitamins that are known to boost the immune system, with an additional benefit of possessing antiviral properties [4]. In fact, sales of dietary supplements such as elderberry and zinc have significantly increased by as much as 255 and $415 \%$, respectively in the single-week period ending March 8, 2020 [5]. Also sitaphal, apple, papaya, broccoli, onion, garlic, green leaves, nuts, ginger, turmeric, pepper, egg yolk, shell fish and mushrooms are some of the miscellaneous dietary supplements which possess a health benefit value [6]. Foods rich in vitamins (such as $\mathrm{C}, \mathrm{A}, \mathrm{D}$ ), functional foods containing fat-soluble compounds (including retinol, retinoic acid, isotretinoin and $\beta$ carotene) and natural polyphenols (such as hesperidin and rutin) are also encouraged to be consumed as preventive measures against COVID-19, with different proposed mechanisms $[5,7,8]$.

Currently, the use of traditional Chinese medicine was found to reduce the severe symptoms of COVID-19 in patients in Chinese hospitals, and its use globally has been proposed. [9]. To our knowledge, a limited number of plant species are being investigated for their beneficial role in the COVID-19 pandemic. Considering that within the Middle East region, including Jordan, traditional herbal medicine used for the treatment of different health conditions are different from those used in Asian countries, the main aim of this study was therefore to present lifestyle practices and preventive measures, including the consumption of dietary supplements, herbs, vitamins and medications by the public in Jordan, in order to boost their immune system during the COVID-19 pandemic.

\section{METHODS}

\section{Study design and questionnaire}

An electronic anonymous survey was designed and distributed through social media platforms during the Corona virus outbreak, and responses were collected from 1st April to 15th May 2020. The survey targeted the public citizens living in all cities of Jordan. The questionnaire was written in Arabic by the principal investigator. The final version of the questionnaire was reviewed by all authors; a few modifications were made to ensure high quality and clarity of the questionnaire items. The questionnaire consisted of three sections: Section 1: Socio-demographic characteristics, including gender, age, and social status, city of residence, level of education and health status were collected.

Section 2: The modifications participants made on their life style practices and any other protective measures needed to avoid the disease transmission were investigated. In addition, the use of herbs, vitamins and food to boost immunity were also investigated. In this section the participant has to select the types of (a) herbal preparations (b) Vitamins (c) food that he/she used during the COVID-19 outbreak from a list of commonly available items in Jordan and the Middle East region. Additionally, the participant has to indicate the method of preparation, regular source of the product(s) and information related to the usefulness for the selected choices. Section 3: The uses of medications to prevent and manage COVID-19 like symptoms were also asked, including NSAIDs, antibiotics, and others. Additionally, participant was asked about their knowledge on the safety and effects of commonly used medications for infections.

\section{Statistical analysis}

Data were analyzed using Statistical Package for Social Science (SPSS), version 22 (SPSS Inc., Chicago, IL, USA). Descriptive analysis was undertaken using mean and standard deviations for continuous variables and percentage for qualitative variables.

\section{Ethical statement}

This research was approved by the ethical committee at the King Abdullah hospital, Jordan University of Science and Technology, Irbid, Jordan, in October/2020, (approval no. $21 / 135 / 2020$ ), and conducted in accordance with the guidelines for human studies as per the FDA Information Sheet Guidance for Institutional Review Board (IRB) Written Procedures: Guidance for Institutions and IRBs [10].

Trop J Pharm Res, September 2021; 20(9): 1970 


\section{RESULTS}

\section{Socio-demographic characteristics}

A total of 1048 Jordanians completed the questionnaire. The demographic data (Table 1) shows that the highest number of participations ( $n=559,53.34 \%$ ) were allocated in Irbid and the second highest number were in the capital Amman ( $n=322,30.73 \%$ ). The majority were females $(75.57 \%)$, within the age group of 18 34 years $(60.31 \%)$, and had a Bachelor's degree or higher (78.82 \%). They were non-smokers $(75.10 \%)$, and with good health conditions (83.11\%).

Table 1: Demographics and characteristics of the study sample

\begin{tabular}{lll}
\hline & $\mathbf{n = 1 0 4 8}$ & $\mathbf{( \% )}$ \\
\hline Gender & & \\
Female & 792 & 75.57 \\
Male & 256 & 24.43 \\
\hline Age group & & \\
18-34 years & 632 & 60.31 \\
35-44 years & 221 & 21.09 \\
45-54 years & 123 & 11.74 \\
55-64 years & 44 & 4.2 \\
$\geq$ 65 & 17 & 1.62 \\
\hline Residential area & & \\
Irbid & 559 & 53.34 \\
Amman & 322 & 30.73 \\
Other cities & 167 & 15.93 \\
\hline Educational level & & \\
High school or less & 96 & 9.16 \\
Diploma & 117 & 11.16 \\
Bachelor's degree & 717 & 68.42 \\
Postgraduate & 109 & 10.4 \\
\hline Health status & & \\
Healthy & 871 & 83.11 \\
Hypertension & 68 & 6.49 \\
Diabetes & 43 & 4.1 \\
Other chronic & & \\
diseases & 66 & 6.30 \\
\hline Smoking status & & \\
Yes & 219 & 20.9 \\
No & 787 & 75.1 \\
\hline Pregnancy status & & \\
Yes & 30 & 2.86 \\
No & 529 & 50.48 \\
\hline
\end{tabular}

Life-style preventive measures used to avoid the transmission of corona virus

During the quarantine period, participants made a number of modifications to their life style practices to prevent the transmission of the corona virus (Figure 1). The majority of the participants $(75.29 \%)$ indicated that staying at home and social distancing would be their best protective measures, when were combined with hygienic practices and disinfection of their surroundings $(71.28 \%)$. Increase in the consumption of hot beverages and tea, medicinal herbs and vitamins, along with an increase in physical exercise were also reported. The consumption of medications that boost the immune system was not highly used by these participants.

\section{Herbal remedies, vitamins and food items consumed to enhance the immune system}

During the quarantine period, responses given by the participants on the use of herbal remedies, vitamins and food items to enhance their immunity are shown in Figure 2. Of the herbal drugs, the most commonly consumed herbs were ginger $(49.05 \%)$, followed by mint $(45.23 \%)$, anise $(40.74 \%)$, green tea $(36.45 \%)$ and sage $(34.83 \%)$. Herbs were mainly used in the form of crude drugs, mostly prepared by boiling or steeping in water. These remedies were used on a regular basis; methods of preparation were based on information obtained from the internet or TV programs (Supplementary 1, Table 2).

Regarding the vitamins and minerals (Figure 3); vitamins $D, C$ and $E$ supplements were used by $52.48,34.35$ and $6.30 \%$; respectively, in addition to multivitamins preparations. Minerals including Zinc, Magnesium and selenium were not commonly consumed among these participants. Vitamin and minerals consumption were enhanced by including food items containing the vitamins into their diet plans, or as dietary supplements in pharmaceutical dosage forms such as tablets or capsules (Supplementary 1, Table 2). These supplements were used with higher frequency during the last 3-6 months prior to the study period.

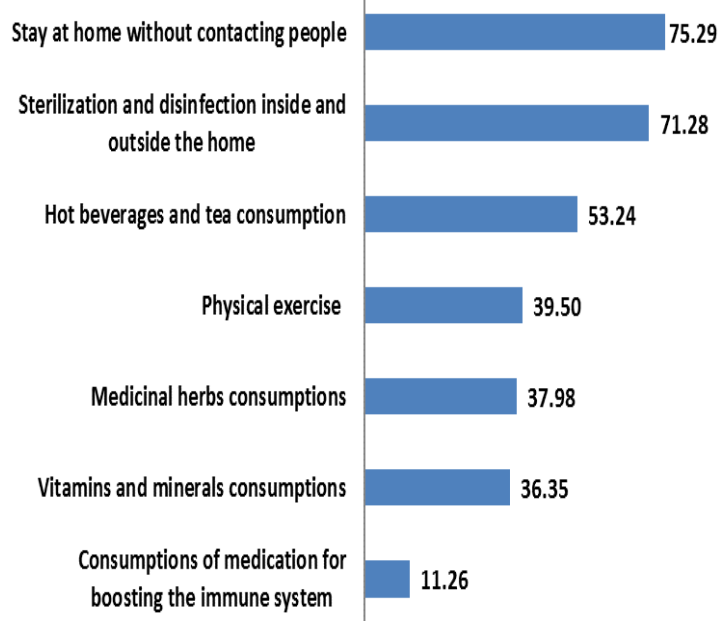

Figure 1: Modified life style practices (\%) followed to strengthen the immune system against corona virus during the quarantine period

Trop J Pharm Res, September 2021; 20(9): 1971 


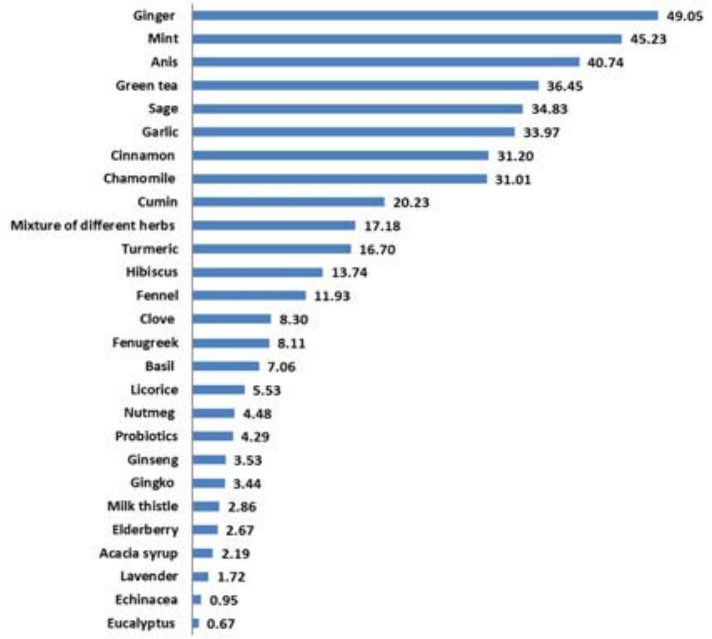

Figure 2: Herbal products (\%) used to strengthen the immune system against corona virus during the quarantine period

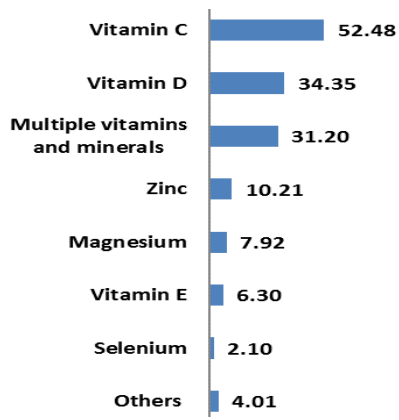

Figure 3: The (\%) of people used vitamins and minerals supplements in order to strengthen the immune system against corona virus during the quarantine period

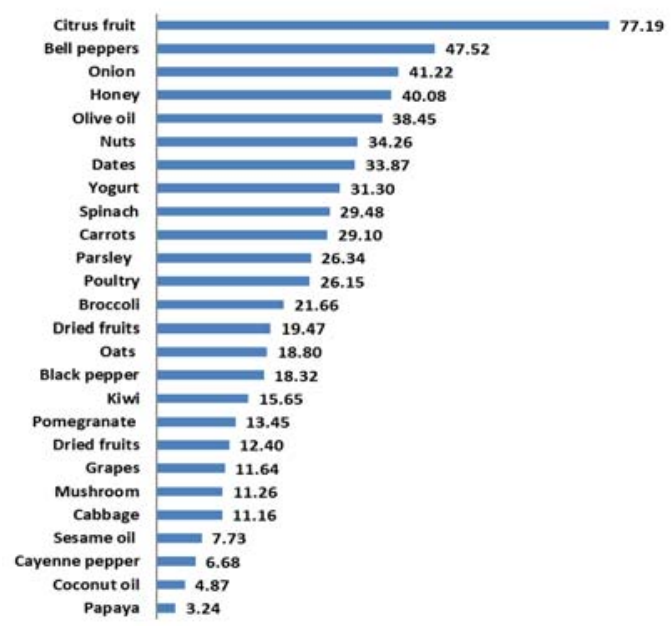

Figure 4: Food items consumed (\%) to strengthen the immune system against corona virus during the quarantine period
Participants who indicated their preferred choices within the presented food items (Figure 4), revealed that citrus fruits were at the top of the list $(77.19 \%)$, followed by bell peppers (47.52 $\%)$, onions (41.22\%), honey (40.08\%), olive oil $(38.45 \%)$, nuts $(34.62 \%)$ and dates $(33.87 \%)$ were all commonly consumed.

\section{Medication use and safety among public during the quarantine period}

When participants were asked about their use of medications for prevention and control of influenza-like symptoms, around $66 \%$ responded that they would consume food rich with vitamin $\mathrm{C}$ and hot herbal beverages, collectively. Around $13.26 \%$ used antibiotics and $17.86 \%$ used paracetamol (acetaminophen) (Figure $5 \mathrm{~A}$ ). Moreover, more than half of participants $(61.16 \%)$ were aware that it is not recommended that antibiotics be taken for viral infections. Similarly, $63.93 \%$ of the participants were aware of the effect of non-steroidal antiinflammatory drugs (NSAIDs) on immunity responses. Regarding interactions between drugs and herbal products, $42.56 \%$ of the participants agreed that interactions may happen compared to $7.4 \%$ who did not agree and 49.90 $\%$ who responded," do not know". Finally, 58.54 $\%$ of the participants were aware that paracetamol is considered safe during pregnancy (Figure 5B).

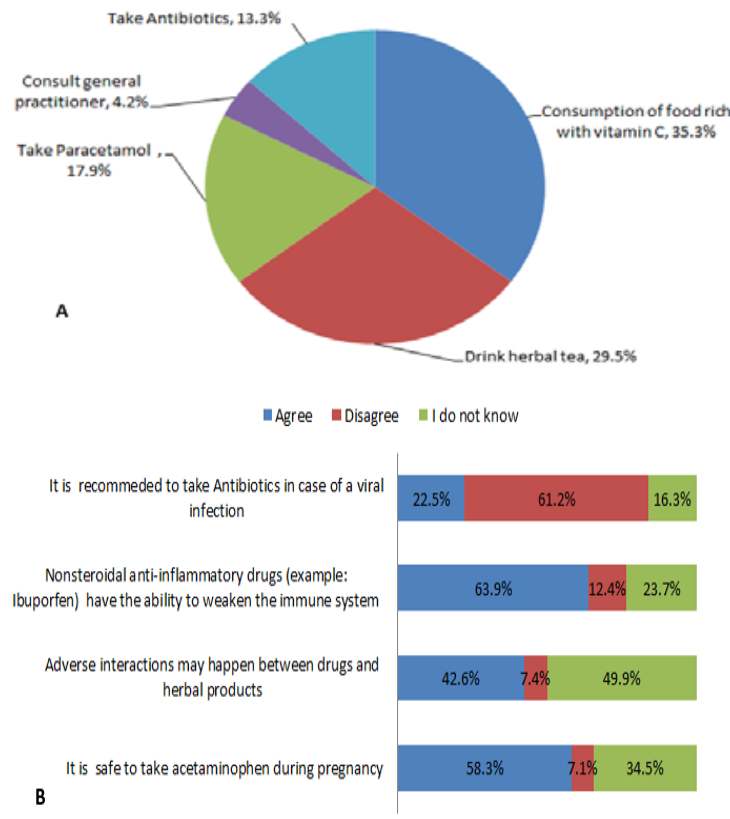

Figure 5: A. Practices among public for management of influenza-like symptoms during the quarantine period. B. Awareness of public towards drugs use and safety for management of influenza-like symptoms during the quarantine period

Trop J Pharm Res, September 2021; 20(9): 1972 


\section{DISCUSSION}

The knowledge and recommendations made with regards to COVID-19 is rapidly changing, and it should be applied carefully with only deep understanding for the mechanisms leading to COVID-19 infection and the intended intervention [6]. Therefore, holistic approaches based on the use of herbal remedies, dietary supplements, as well as proper diet plans composed of varied food items are highly beneficial and recommended during this pandemic [7].

A social distancing helps to avoid close contact with symptomatic and asymptomatic individuals, as well as hygienic practices, and this would determine the individual's risk of COVID-19 infection [11]. This work states that lifestyle practices and preventive measures used to prevent the disease transmission were followed properly by the study population, and as per the recommendations made by the Centers for Disease Control and Prevention [12]. Historically, herbal medicines are considered to play a major role in controlling infectious disease transmission, by acting as antiviral agents as well as boosting the immune system [13]. In agreement with the previous review by Suchitra et al [4], ginger, mint, anise, green tea and sage were frequently used as effective agents to counter viral illness and their ill effects. Among the study participants, herbs with well-known immune boosting effects were consumed in moderate to low portions, indicating that there is a shortage in the knowledge of their benefits during this time of the disease spread. In this study, consumption of vitamin and mineral supplements was enhanced during this time, with special focus on vitamins $C$ and D. In Jordan, deficiency of vitamin $D$, which is known to aid good immune function, is common especially during winter [14]. There is a good evidence that vitamin $\mathrm{D}$ deficiency contributes to the seasonal increase in virus infections of the respiratory tract, from the common cold to influenza, and now during COVID-19 [15]. Therefore, it is particularly important for those self-isolating with limited exposure to sunlight to consider supplementation with vitamin D. In addition to the well-known health benefits of sustained healthy diet, all the food items list presented in this study play an important role in minimizing the effect of this pandemic, due to its content with varied natural constituents including, vitamins, minerals, amino acids, polyphenols, flavonoids as well as other antioxidants and tonics that enhance the immune system [4]. In this study, citrus fruit consumption was favorable by the majority over the other food items due to its high content of vitamin $\mathrm{C}$, fiber and flavonoids.

In this study, majority of participants tended not to use antibiotics and NSAIDs in situations where they experienced flu-like symptoms. Prior antibiotic exposure has been shown to be the most frequent risk factor in the development of community-acquired respiratory infections caused by drug-resistant Streptococcus pneumonia [16]. Current clinical guidelines including prescribing policy indicate that in the case of suspected viral infection, rapid tests should be made to confirm clinical diagnosis and support evidence to use antiviral agents, and do not recommend the use of antibiotics [17]. Administration of Ibuprofen during the first stages of inflammation can have repercussions on the immune system by interfering with optimal antibody production [18]. French reports were the first to discover serious infection complications that occurred in patients receiving NSAIDs, mainly Ibuprofen and Ketoprofen, used in the treatment of fever and pain. Instead, it recommended the use of paracetamol in patients with COVID-19 [19].

\section{Limitations of the study}

One of the study limitations is that participation was limited to Jordanian people, who have access to internet. In addition, the public who were of advanced age or no digital skills might be underrepresented. Another limitation was that data was collected at a single point in time. Future studies are required to track changes in public practices.

\section{CONCLUSION}

The findings of this study show that people living in Jordan carefully make their choices on the consumption of herbal and vitamins products, food and medications intake, combined with good lifestyle practices, including social distancing and hygienic practices, with the aim of boosting their immunity, and slowing the spread of the corona virus during the COVID-19 pandemic. Nevertheless, public knowledge and information on the role of other available supplementations of herbs, vitamins and minerals need to be expanded. In this regard, healthcare professionals may need to take the responsibility for educating the public about different available preventive measures, in addition to the rational use of medications commonly used for the treatment of infectious diseases, especially during pandemics. 


\section{DECLARATIONS}

\section{Acknowledgement}

The authors would like to thank the participants in this study who filled the questionnaire and shared the link of the survey with others.

\section{Conflict of interest}

No conflict of interest is associated with this work.

\section{Contribution of authors}

We declare that this work was done by the authors named in this article and all liabilities pertaining to claims relating to the content of this article will be borne by the authors. Reem Issa was involved in conceptualization, and preparation of the original draft. The authors Dima Albalas, and Alaa Yehya were involved in methodology design, writing- reviewing and editing the manuscript. Fayez Shriedeh performed the statistical analysis. All authors provided critical inputs, edited, and revised the article.

\section{Open Access}

This is an Open Access article that uses a funding model which does not charge readers or their institutions for access and distributed under the terms of the Creative Commons Attribution License (http://creativecommons.org/licenses/by/ 4.0) and the Budapest Open Access Initiative (http://www.budapestopenaccessinitiative.org/rea d), which permit unrestricted use, distribution, and reproduction in any medium, provided the original work is properly credited.

\section{REFERENCES}

1. World Health Organization (WHO). Novel Coronavirus (2019-nCoV): situation report 2020, 3.

2. Guzik TJ, Mohiddin SA, Dimarco A, Patel V, Savvatis $K$ Marelli-Berg FM, Madhur MS, Tomaszewski M, Maffia $P$, D'Acquisto F, et al. COVID-19 and the cardiovascular system: implications for risk assessment, diagnosis, and treatment options. Cardiovasc Res 2020, 116 (10): 1666-1687.

3. Shi Y, Wang Y, Shao C, Huang J, Gan J, Huang X, Bucci $E$, Piacentini $M$, Ippolito $G$, Melino G. COVID-19 infection: the perspectives on immune responses. Cell Death Differ 2020, 27:1451-1454.
4. Suchitra MR, Parthasarathy S. JIJoRiPS. Nutrition and corona virus: Plan a diet in a pandemic. INT J RES MARK Int J Res Pharm Sci 2020, 11(1): 4-10.

5. Adem S, Eyupoglu V, Sarfraz I, Rasul A, Ali M. Identification of potent COVID-19 main protease (Mpro) inhibitors from natural polyphenols: An in-silico strategy unveils a hope against CORONA. Preprints 2020, 2020030333.

6. Galanakis CM. The Food Systems in the Era of the Coronavirus (COVID-19) Pandemic Crisis. Foods 2020, 9(4): 523-533.

7. Naik SR, Thakare VN, Joshi FP. Functional foods and herbs as potential immunoadjuvants and medicines in maintaining healthy immune system. A commentary $\mathrm{J}$ Complement Integr Med 2010, 7(1). https://doi.org/10.2202/1553-3840.1441.

8. Gibson A, Edgar JD, Neville CE, Gilchrist SE, McKinley MC, Patterson CC, Young IS, Woodside JV. Effect of fruit and vegetable consumption on immune function in older people: a randomized controlled trial. Am J Clin Nutr 2012, 96 (6):1429-1436.

9. $X u J$, Zhang $Y$. Traditional Chinese medicine treatment of COVID-19. Complement Ther Clin 2020, 39: 101165.

10. https://www.fda.gov/regulatory-information/search-fdaguidance-documents/institutional-review-board-irbwritten-procedures

11. Gasmi A, Noor S, Tippairote T, Dadar M, Menzel A, Bjørklund G. JCl. Individual risk management strategy and potential therapeutic options for the COVID-19 pandemic. Clin Immunol 2020, 108409.

12. CDC COVID-19 RESPONSE TEAM. Severe outcomes among patients with coronavirus disease 2019 (COVID19)_United States, February 12-March 16, 2020. MMWR Morb Mortal Wkly Rep 2020, 69(12): 343-346.

13. Sorensen A, van Beest FM, Brook RK. JPvm. Impacts of wildlife baiting and supplemental feeding on infectious disease transmission risk: a synthesis of knowledge. Prev Vet Med 2014, 113(4): 356-363.

14. El-Khateeb $M$, Khader $Y$, Batieha $A$, Jaddou $H$, Hyassat $D$, Khawaja $N$, Abujbara $M$, Ajlouniet K. Vitamin $D$ deficiency and associated factors in Jordan. SAGE Open Med 2019, 7: 2050312119876151.

15. Kohlmeier M. Avoidance of vitamin $D$ deficiency to slow the COVID-19 pandemic. BMJ Nutrit Prevent Health 2020, 3(1): 67-96.

16. Shiley KT, Lautenbach E, Lee I. Epidemiology $H$. The use of antimicrobial agents after diagnosis of viral respiratory tract infections in hospitalized adults: antibiotics or anxiolytics? Infect Control Hosp Epidemiol 2010, 31(11): 1177-1183.

17. Uyeki TM, Bernstein HH, Bradley JS, Englund JA, File Jr TM, Fry AM, Gravenstein S, Hayden FG, SA Harper, JM Hirshon, et al. Clinical practice guidelines by the Infectious Diseases Society of America: 2018 update on diagnosis, treatment, chemoprophylaxis, and institutional outbreak management of seasonal influenza. Clin Infect Dis 2019, 68(6): e1-e47.

18. Chaiamnuay S, Allison JJ, Curtis JR. Risks versus benefits of cyclooxygenase-2-selective nonsteroidal anti-inflammatory drugs. Am J Health Syst Pharm 2006, 63(19): 1837-1851.

19. Little $P$. Non-steroidal anti-inflammatory drugs and covid19. Brit Med J Publishing Group (BMJ) 2020 368:m1185. 